\title{
Ultrastructure of the cirrus sac of the male strobila of Shipleya inermis (Fuhrmann, 1908) (Cestoda: Cyclophyllidea)
}

\author{
L. G. PODDUBNAYA ${ }^{1 *}$, N. A. POSPEKHOVA ${ }^{2}$
}

${ }^{1 *}$ I. D. Papanin Institute for Biology of Inland Waters, Russian Academy of Sciences, 152742, Borok, Yaroslavl Province, Russia, E-mail: poddubny@ibiw.yaroslavl.ru; ${ }^{2}$ Institute of Biological Problems of the North, Russian Academy of Sciences, 685000, Portovaya Str. 18, Magadan, Russia, E-mail: posna@ibpn.ru

\begin{abstract}
Summary
This study was designed to provide information on the ultrastructural traits of the cirrus sac of the male strobila of the dioecious cyclophyllidean tapeworm, Shipleya inermis Fuhrmann, 1908 from the small intestine of long-billed dowitchers, Limnodromus scolopaceus, in Chukotka, Russia. The cirrus sac is characterised by a thick muscular wall (comprising about 20 layers of longitudinal muscles) with the muscle cells being located outside the wall along the peripheral muscle layer and the presence of a thick, fibrillar septum inside the sac along the inner muscle layer of the wall. The epithelium of the intrabursal ducts is syncytial and has sunken perikarya. The ejaculatory duct is characterised by surface luminal microvilli and a large number of the sunken perikarya producing electron-dense secretory granules, which discharge into the duct lumen as an apocrine secretion. The cirrus is armed with two types of sclerotized structures formed by its epithelium, hooks of about $25 \mu \mathrm{m}$ in length and microthrix-like structures on its luminal surface. The hooks are sigmoid in shape, have a blade circular in transverse section and about $3.5 \mu \mathrm{m}$ in width, and taper at both extremities. The hook body consists of moderately electron-dense material mixed with a more electron-dense material and an electron-lucent core. The hook roots lie within the cirrus epithelium, where their lateral margins are composed of a thin covering of electron-dense material with narrow lateral extensions. The usefulness of the ultrastructural characters of the cirrus sac as indicators of phylogenetic relationships within the Eucestoda is discussed.
\end{abstract}

Keywords: ultrastructure; cirrus sac; male ducts; accessory glands; Shipleya inermis; Cyclophyllidea

\section{Introduction}

The usefulness of the ultrastructural features of the copulatory organ (especially the hard parts) of platyhelminths as an additional source of systematic characters has been demonstrated for free-living forms by Doe (1982), Martens and Schockaert (1981) and Martens (1984, 1986). Studies of the hard parts of the male terminal organ of tapeworms have confirmed their great variability (see Poddubnaya \& Mackiewicz, 2009). Our knowledge of the ultrastructure of the cirrus sac of 'higher' tapeworms is poor. Some papers have been published on the structure of the copulatory part of the male reproductive system using transmission (TEM) and scanning (SEM) electron microscopy for species of the family Hymenolepididae, i.e. Hymenolepis diminuta (see Lumsden \& Specian, 1980), Sobolevicanthus gracilis (see Cielecka et al., 1994; Davydov \& Korneva, 2002), Parabisacanthes philactes and P. japonicus (see Czapliński et al., 1984), and a species of the family Nematotaeniidae, i.e. Cylindrotaenia hickmani (see Jones, 1989). With the aim of looking for new information on the cirrus sac of 'higher' tapeworms, in this paper special attention is paid to Shipleya inermis Fuhrman, 1908 (Dioecocestidae), or according to Schell (1959), 'the Shipleya enigma'. This cestode species is considered as being protandrous (Baer, 1940; Schell, 1959) or dioecious (Burt, 1939; Voge \& Rausch, 1956; Coil, 1970; Ryzhikov \& Tolkacheva, 1981), i.e. with some exceptions there is a pairing of males and females in each host. Five types of strobilae with well-developed cirrus sacs were distinguished in S. inermis on the basis of functional and morphological characteristics by Rausch and Rausch (1990). Didyk and Burt (1998) also noted five types of strobilae in this species and suggested that these tapeworms are protogynous hermaphrodites that usually become regionally dioecious, possibly in response to some form of interaction between individuals. The suggestion has also been made that extragenital insemination (referred to as hypodermic insemination by Smith \& McManus, 1989) occurs in $S$. inermis, as the distal part of the vagina is reduced (Spasski \& Gubanov, 1959; Coil, 1970). 
In the present study, a detailed description is given of the cirrus sac of male $S$. inermis with the main objectives of revealing characteristics of the epithelial wall of the cirrus, the armature of the cirrus, the ejaculatory duct, the internal seminal vesicle and the cirrus sac wall itself.

\section{Materials and Methods}

Adult specimens of male Shipleya inermis from the small intestine of long-billed dowitchers, Limnodromus scolopaceus (Say), were collected in the northwestern Chukotka, Russia. Live worms were fixed in $4 \%$ glutaraldehyde in $0.1 \mathrm{M}$ phosphate buffer at $\mathrm{pH} 7.2$ for $20-30$ days at $4{ }^{\circ} \mathrm{C}$. Postfixation was carried out in $2 \%$ osmium tetroxide in the same buffer for $12 \mathrm{~h}$ at $4{ }^{\circ} \mathrm{C}$ and stained with uranyl acetate for 6 hours. The material was then dehydrated in a graded series of ethanol and acetone, and then embedded in Epon and Araldite. Ultrathin sections $(70-90 \mathrm{~nm})$ were examined using a JEM-1011 transmission electron microscope (TEM) operating at $80 \mathrm{kV}$.

\section{Results}

Based on TEM measurement of longitudinal sections, the cirrus sac of male Shipleya inermis is large, about $800 \mu \mathrm{m}$ long and $190 \mu \mathrm{m}$ wide. It is surrounded by a thick muscular cirrus sac wall of about $20 \mu \mathrm{m}$ in width, which is thinner at its proximal and distal ends (Figs. 1A, B). Within the distal part of the cirrus sac is an invaginated cirrus of about $200 \mu \mathrm{m}$ in length (Figs. 1B, D). The middle and proximal regions of the cirrus sac are occupied by an ejaculatory duct, which arises from a small internal seminal vesicle present at the proximal end of the sac (Figs. 1B, C).

Cirrus sac wall

The cirrus sac wall of $S$. inermis includes up to 20 layers of muscle fibres that are mainly directed longitudinally (Fig. 1A). The muscle cells involved in the formation of this muscle sheath are situated on the outer wall (Fig. 1A). They can be recognized by having large nuclei with a prominent nucleolus and an electron-dense perinuclear cytoplasm that is filled with enlarged cisternae of granular endoplasmic reticulum (GER). The fibres of the muscle sheath are separated from each other by thin areas of fibrillar intracellular matrix (Fig. 1A). This matrix also fills a thick layer (about $3.8 \mu \mathrm{m}$ wide), which forms the inner lining (septum) of the sac (Fig. 1A). Electron-dense condensations are apparent in the moderately electron-dense fibrillar material of this layer and its nucleated regions are adjoined on its internal surface (Fig. 1A).

Internal seminal vesicle and ejaculatory duct with associated cells

$S$. inermis has short internal seminal vesicle of about 50 $\mu \mathrm{m}$ in length (Fig. 1C). This enlarged duct is composed of a thin electron-dense syncytial epithelial cytoplasm supported by a thin, fibrous matrix and two or three layers of longitudinal muscles (Fig. 2A). Associated muscle cells are distributed throughout the cirrus sac. Sunken epithelial cytons lie around this duct within the cirrus sac (Fig. 1C). Spermatozoa were observed within the lumen of the vesicle (Figs. 1C, 2A)

The ejaculatory duct occupies most of the central space within the cirrus sac (Fig. 1B). It is lined by a thin anuclear syncytial epithelium, which rests on a thin fibrous matrix and is supplied with two well-developed muscle layers comprising longitudinal and circular muscles (Fig. 2D, F). The large, sunken epithelial cytons of this duct are variable in shape and occupy much of the proximal and middle regions of the cirrus sac $(1 \mathrm{~B}, 2 \mathrm{~B})$. The relatively dense perinuclear cytoplasm of these cytons exhibits ribosomes, GER, Golgi complexes and mitochondria (Fig. 2C). Together with epithelial rod-shaped electron-dense bodies, the spherical (about $0.35 \mu \mathrm{m}$ in diameter) and ellipsoidal $(0.35 \times 0.0 .2 \mu \mathrm{m}$ in diameter) electron-dense bodies are produced within their cytoplasm and are present in various locations of the cytoplasm (Fig. 2D, F). The projections from these epithelial cells filled with these electron-dense bodies connect with the epithelial lining of the ejaculatory duct; these are more numerous in the middle-distal portion of the ejaculatory duct. The electron-dense bodies are transported through these processes into the ejaculatory duct epithelium (Fig. 2D.F) being visible along the whole length of the epithelial cytoplasm. They are then released into the lumen of the ejaculatory duct as an apocrine secretion enclosed in small epithelial evaginations of the apical epithelial cytoplasm (Fig. 2F). The luminal plasma membrane of the proximal and middle parts of the ejaculatory epithelium is lined by microvilli containing a distinct core tunic (Fig. 2E). Distally, prior to the cirrus, the microvilli disappear, and the luminal surface begins to be smooth. The lumen of the ejaculatory duct is almost entirely filled by the moderately electron-dense homogenous material, and numerous fragments of epithelial cytoplasm with dense bodies were observed close to the luminal wall (Figs. 1C, 2F).

\section{Cirrus epithelium}

The epithelial anuclear wall of the invaginated cirrus of $S$. inermis can easily be recognized by the presence of large hooks along its cytoplasmic lining (Figs. 1D, 3A). The uniform syncytial cytoplasm of this region is thicker than the adjacent region of the ejaculatory duct and the fibrous matrix surrounding this duct is extremely thick in comparison with that which surrounds the ejaculatory duct (Fig. 4A). Circular myofibrils run through this fibrous matrix, beneath which longitudinal muscle layers are localized (Fig. 4A). The epithelial cytons of the cirrus epithelium are located deep within the cirrus sac beneath the fibrous matrix and muscle layers, possess irregularly shaped nuclei and are connected to the cirrus wall by cytoplasmic processes (Fig. 4A, B). Both the perinuclear cytoplasm and cytoplasmic processes contain the same types of the rod-shaped electron-dense bodies and vesicles produced by the epithelial cytons and which fill the epithelial lining of the cirrus (Fig. 4A, C). The cirrus epithelial cytoplasm contains numerous rod-shaped electron-dense bodies 
and vesicles of various sizes, shapes and contents (Figs. 3A, E, 4A). Distally, such bodies are absent from the epithelial cytoplasm, and the folded apical plasma membrane forms deep, branched invaginations into the epithelial cytoplasm, dividing the apical cytoplasmic region into various outgrowths, on the tapered luminal surfaces of which the electron-dense accumulations were observed (Fig. 3B - D, F). In longitudinal sections these apical structures have a microthrix-like shape similar to that of a spiniform microtriches (Fig. 3B, C, F). Their electrondense cap is about $4 \mu \mathrm{m}$ in length and circular in cross-sections with a moderately electron-dense core (Fig. 3D). The base of these microthrix-like structures appears to be formed from of the apical outgrowths (Fig. 3C, F). There is no basal plate between the base and cap of these structures. The epithelial cell bodies and muscle cells that surround the cirrus have lamella-like processes that fill the space between the cellular components within the cirrus sac (Fig. 4B).

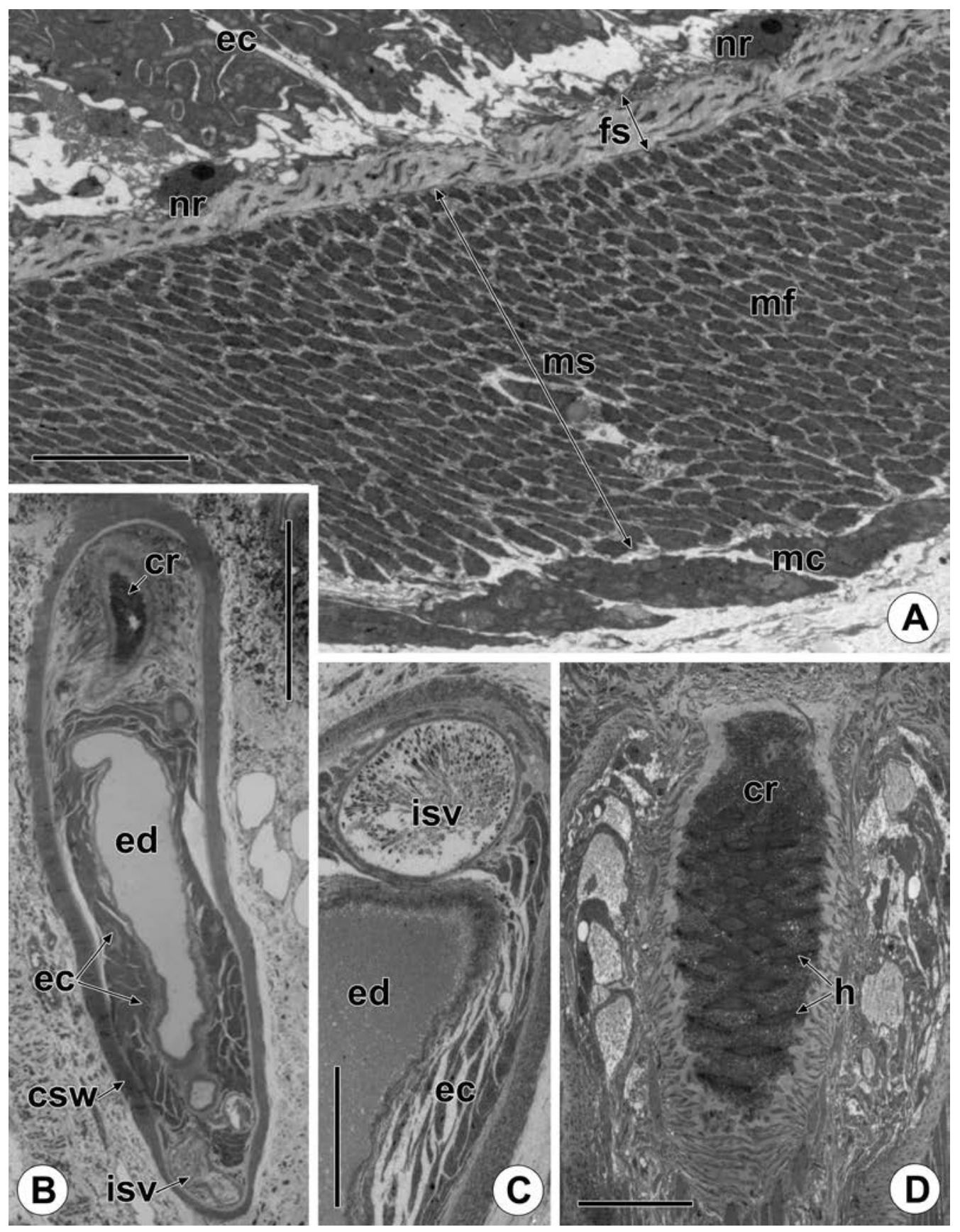

Fig. 1. Cirrus sac components of Shipleya inermis. A - cirrus sac wall (scale bar $=10 \mu \mathrm{m}$ ); B - view of the cirrus sac (scale bar $=200 \mu \mathrm{m})$; - view of the proximal cirrus sac portion showing internal seminal vesicle and part of the ejaculatory duct (scale bar $=50 \mu \mathrm{m}$ ); $\mathrm{D}$ - view of the distal region of the cirrus sac showing the cirrus with hooks and surrounding duct components (scale bar $=20 \mu \mathrm{m}$ )

Abbreviations: csw - cirrus sac wall; cr - cirrus; ec - ejaculatory duct cells; ed - ejaculatory duct; fs - fibrillar septum; $\mathrm{h}$ - hook; isv - inner seminal vesicle; mc - muscle cell; $\mathrm{mf}$ - muscle fibres; ms - muscle sheath; $\mathrm{nr}$ - nucleated region 


\section{Cirrus hooks}

The hooks are about $25 \mu \mathrm{m}$ in length, and the distance between the hooks is almost $2 \mu \mathrm{m}$ (Figs. 3A, 4A). In the most distal and proximal zones of the cirrus epithelium the hooks tend to be shorter (Fig. 3A). The hook roots lie within the wall of the cirrus, occupying practically the entire thickness (Figs. 3A, 4A). The hooks are sigmoid in shape with a slight curve in the region between hook root and its blade and another in the blade before it tapers to towards the apex (Fig. 3A, B). TEM sections show that the hooks measure $3.5 \mu \mathrm{m}$ wide throughout most of their middle region and then narrow towards the extremities (Figs. $3 \mathrm{~A}, \mathrm{~B}, 4 \mathrm{~A})$. The hook blade is almost circular in transverse sections (Fig. 3D).
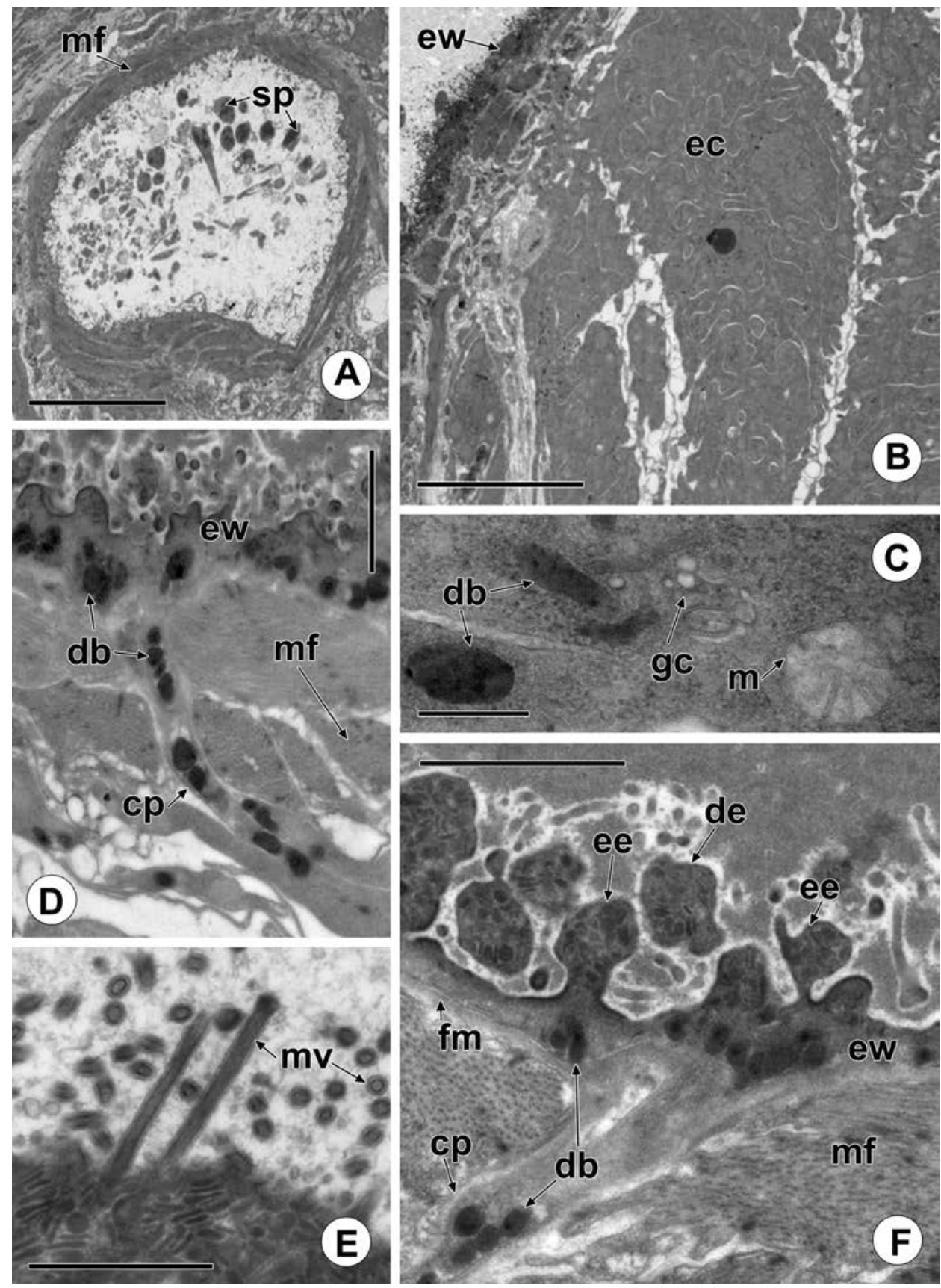

Fig. 2. Ejaculatory duct of Shipleya inermis. A - view of the internal seminal vesicle surrounded by muscle layer and containing spermatozoa in its lumen $($ scale bar $=10 \mu \mathrm{m})$; B - view of ejaculatory duct and its large accessory cells (scale bar $=10 \mu \mathrm{m}$ ); - cytoplasm of an accessory cell with electron-dense granules, Golgi complex and mitochondrion (scale bar $=0.5 \mu \mathrm{m}$ ); D - cell projection with electron-dense granules connecting accessory cells with the epithelial wall (scale bars $=2 \mu \mathrm{m}$ ); E - microvilli on the surface of the proximal region of the ejaculatory duct portion, note that the epithelial cytoplasm contains numerous rod-shaped bodies (scale bar $=1 \mu \mathrm{m}$ ); F - apocrine secretion of the epithelial cell bodies into the lumen (scale bar $=2 \mu \mathrm{m})$

Abbreviations: $\mathrm{cp}$ - cell projection; db - dense bodies; de - discharged evagination; ec - ejaculatory duct cells; ee - evagination of epithelial wall; ew - epithelial wall; fm - fibrillar matrix; gc - Golgi complex; $\mathrm{m}$ - mitochondrion; $\mathrm{mf}$ - muscle fibres; mv - microvilli; sp - spermatozoa 
Each hook consists mainly of a moderately electron-dense substance that is sometimes mixed with electron-dense material (Fig. 3A, B), and an electron-lucent core (Fig. 3A, $D)$. At the edges of the root a thin layer of electron-dense material was observed (Figs. 3A, E, 4A). Proximally, along the root margin opposite the curvature of the blade, project irregular, short, narrow electron-dense lateral extensions
(Figs. 3A, E, 4A), and close to them are cytoplasmic electron-dense bodies (Fig. 3E). Distally, from the point where the body of the hook fuses with the epithelial plasma membrane the root is modified to form the blade. The epithelial membrane then runs along the blade surface until the latter projects into the cirrus lumen (Fig. 3A, B, D).

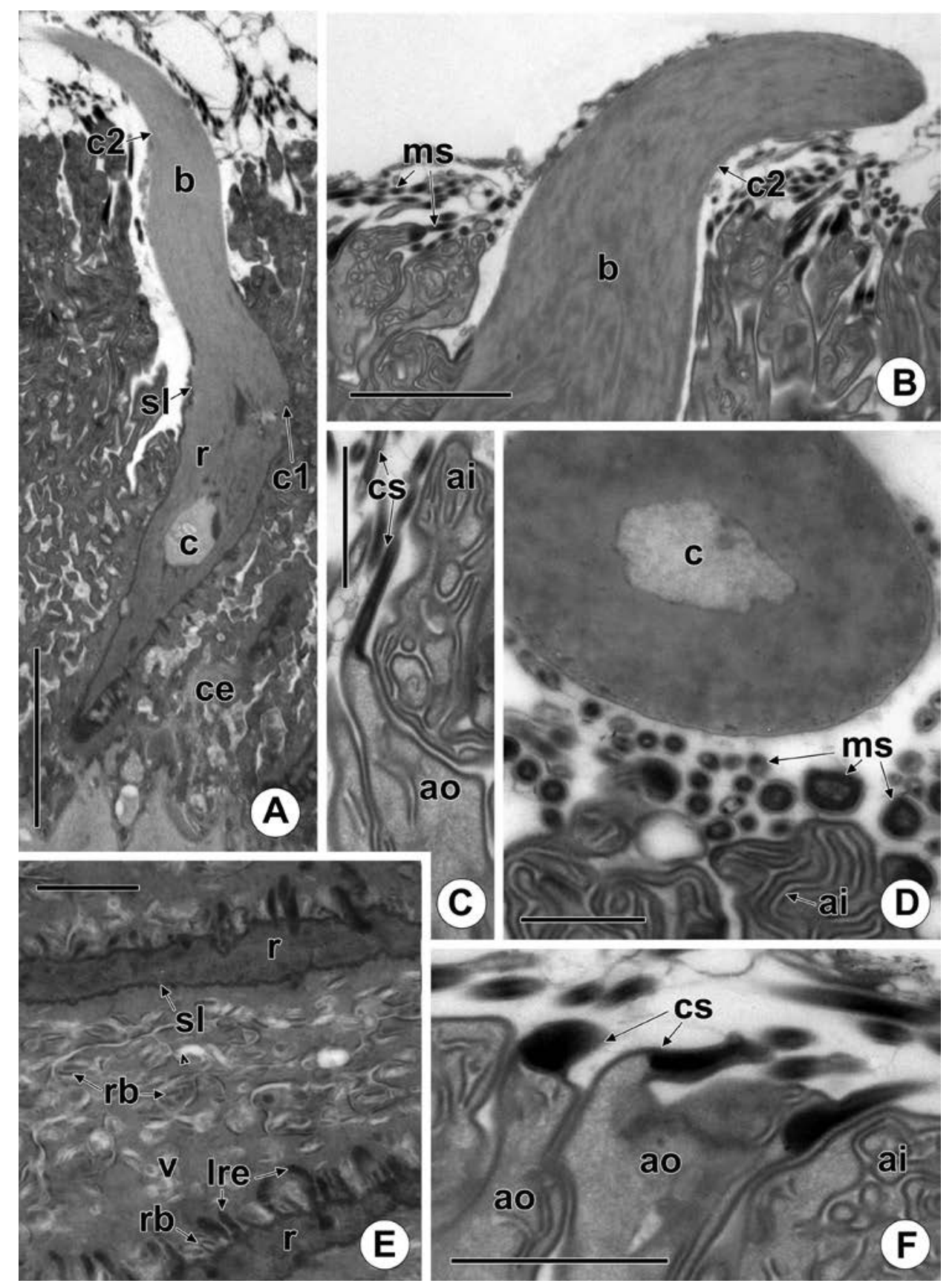

Fig. 3. Hard structures of the cirrus of Shipleya inermis. A - saggital section through a cirrus hook showing its root, blade and two curves along its length (scale bar $=5 \mu \mathrm{m}$ ); B - longitudinal section of the curved blade protruding into the cirrus lumen (scale bar $=2 \mu \mathrm{m}$ ); $\mathrm{C}$ - microthrix-like structure on the tapered apical surface of an outgrowth, note the deep branched apical invaginations of the plasma membrane $($ scale bar = $1 \mu \mathrm{m})$; D transverse section through a blade of the hook and microthrix-like structures, note the electron-lucent core within the blade (scale bar $=0.5 \mu \mathrm{m})$; E section through parts of two hook roots showing a thin electron dense surface layer, smooth on one side and with narrow electron-dense extensions from this layer on the other side (scale bar $=1 \mu \mathrm{m}) ; \mathrm{F}$, microthrix-like structures (scale bar $=1 \mu \mathrm{m}$ )

Abbreviations: ai - apical invagination; ao - apical outgrowth; $\mathrm{b}$ - blade; $\mathrm{c}$ - electron-lucent core of the hook; $\mathrm{c}$ - curve between hook root and blade; c2 - curve of the blade; ce - cirrus epithelium; cs - cap microthrix-like structures; lre - lateral extensions of electron-dense surface layer of the 178 root; $\mathrm{r}$ - root; rb - rod-shaped electron-dense bodies; sl - surface electron-dense layer; $\mathrm{v}$ - vesicles 


\section{Nerve elements}

The syncytial cirrus epithelium of $S$. inermis is continuous with that of the tegumental epithelial layer of the body wall. The syncytial cytoplasm of transition zone between these two regions, i.e. immediately beyond the invaginated cirrus, lacks the hooks and microthrix-like electron-dense structures and instead becomes unfolded and smooth (Fig. $4 \mathrm{E})$. Distally, the structure of the syncytial cytoplasm re- sembles that of the tegument, as the epithelium bears microtriches (Fig. 4E). The tegumental cytoplasm of the body wall around the cirrus invagination is well supplied with ciliated and unciliated sensory endings that are arranged in the ring around genital pore (Fig. 4F). Numerous nerve fibres, containing large dense vesicles, are distributed between the muscle bundles and layer of fibrous matrix of the wall and within cirrus sac of $S$. inermis (Fig. 4D).
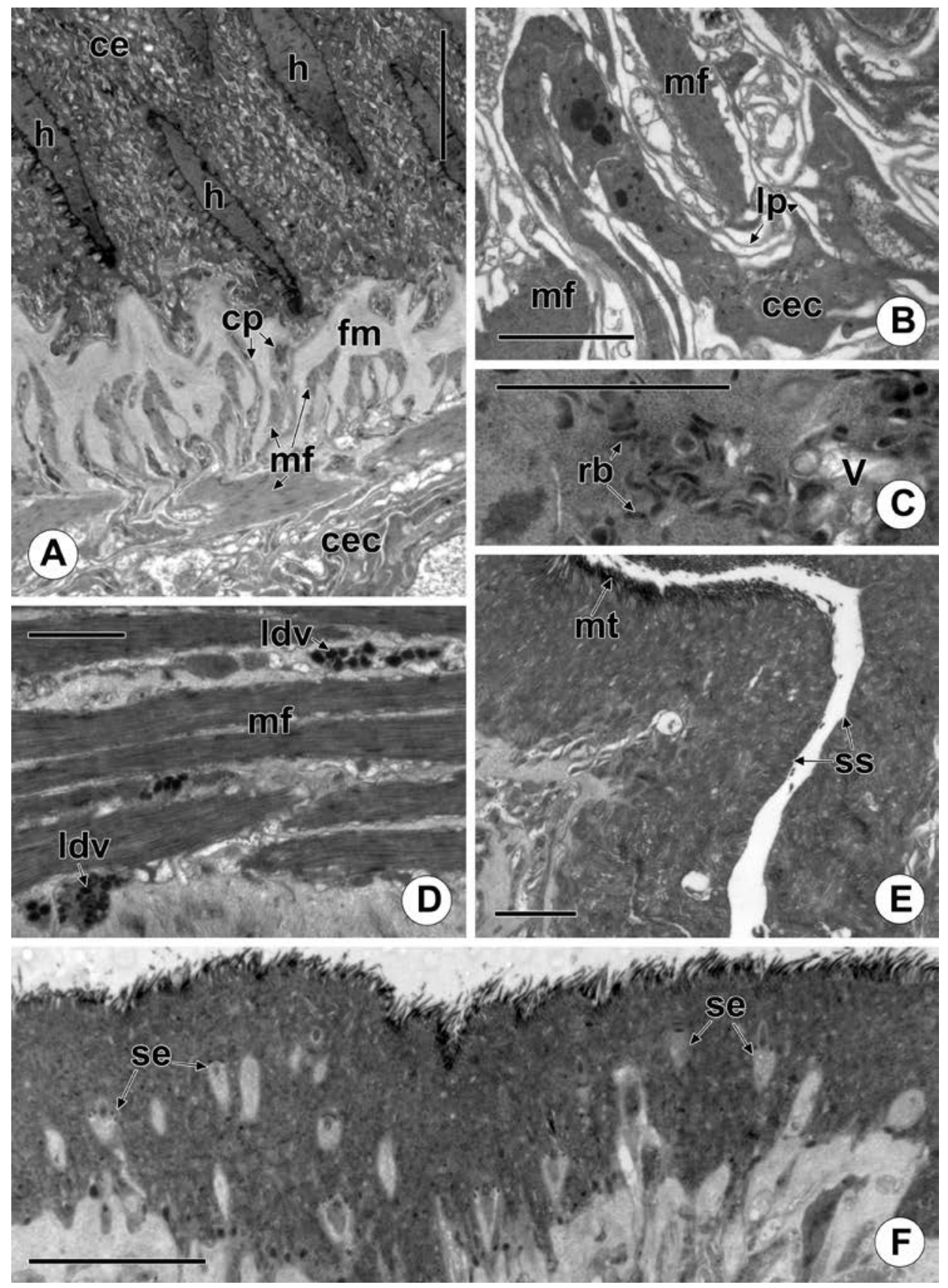

Fig. 4. Cirrus epithelium and cirrus sac innervation of Shipleya inermis. A - Proximal part of the cirrus epithelium showing the distribution of the root hooks, note the thick fibrous matrix and muscle layers (scale bar $=5 \mu \mathrm{m}$ ); B - Cell components of the cirrus sac at the level of the cirrus, note the epithelial cell and muscle fibres with lamella-like processes; (scale bar $=5 \mu \mathrm{m}$ ); $\mathrm{C}$ - Perinuclear cytoplasm of a cirrus epithelial cell filled with rod-shaped dense bodies and vesicles (scale bar $=2 \mu \mathrm{m}$ ); D - Nerve fibres containing large dense vesicles running between the muscle fibres of the cirrus sac wall (scale bar $=2 \mu \mathrm{m}) ; \mathrm{E}$ - Transition zone of the smooth syncytial epithelial cytoplasm between the cirrus and the body epithelium $($ scale bar $=2 \mu \mathrm{m}) ; \mathrm{F}$ - Receptor field around the invaginated cirrus containing different types of sensory endings $($ scale bar $=5 \mu \mathrm{m})$

Abbreviations to: ce - cirrus epithelium; cec - cirrus epithelial cell; $\mathrm{cp}$ - cell projection; fm - fibrillar matrix; $\mathrm{h}$ - hook; ldv - large dense vesicles; lp lamella-like processes; $\mathrm{mf}$ - muscle fibres; $\mathrm{mt}$ - microtriches; rb - rod-shaped electron-dense bodies; se - sensory ending; ss - smooth surface; 


\section{Discussion}

The present investigation provides the first ultrastructural description of the cirrus sac of a species of the genus Shipleya. The cirrus sac of the male strobila of $S$. inermis has a number of ultrastructural characteristic features: (1) the cirrus sac is delimited by a thick muscular wall consisting of about 20 layers of longitudinal muscles that are well supplied with ldv-filled (large dense vesicles) nerve terminals and a thick, inner layer in the form of a fibrous matrix; (2) large epithelial perikarya are present around the ejaculatory duct and produce electron-dense bodies that are discharged into the lumen of this duct via an apocrine mechanism; (3) microvilli occur on the luminal surface of the ejaculatory duct; (4) the cirrus is armed with large hooks approximately $25 \mu \mathrm{m}$ length that are densely distributed along the epithelial wall of the invaginated cirrus; (5): the luminal surface of the cirrus epithelium is covered with microthrix-like structures; and (6) the epithelium of the internal seminal vesicle, ejaculatory duct and cirrus is syncytial with sunken perikarya.

\section{The cirrus sac wall of the tapeworms}

The fine structural analyses of the muscle arrangement of the cirrus sac wall of different tapeworms studied to date by TEM have shown that the most studied members of the orders Caryophyllidea (Davydov et al., 1994; Poddubnaya, 2003b; Poddubnaya et al., 2003), Spathebothriidea (Poddubnaya et al., 2005; Poddubnaya, 2007), Bothriocephalidea (Korneva, 2002; Poddubnaya, 2003 a), Diphyllobothriidea (Poddubnaya, 2002), Proteocephalidea (Korneva \& Davydov, 2001) and Tetraphyllidea (Beveridge \& Smith, 1985) have different numbers of mixed longitudinal and circular muscle layers within their wall musculature. However, in two members of the bothriocephalidean family Echinophallidae the cirrus sac wall consists of two independent bands of muscles, an inner one including numerous layers of longitudinal muscles and an outer band of circular muscles (Levron et al., 2008; Poddubnaya \& Mackiewicz, 2009). It should be emphasized that numerous cell bodies of the muscle cells are localised within the sac wall of these 'lower' tapeworms between the muscle fibres (Poddubnaya et al., 2003, 2005; Poddubnaya \& Mackiewicz, 2009).

With regard to the morphology of the cirrus sac wall of the 'higher' tapeworms, those species examined have exhibited some variability in their sac wall. In Cylindrotaenia hickmani (Nematotaeniidae) the sac wall consists of two or three layers of muscles separated from each other by thin regions of fibrous intracellular matrix (Jones, 1989). In Sobolevicanthus gracilis (Hymenolepididae) the cirrus sac is surrounded by an internal fibrillar matrix and an external layer of longitudinal and circular muscle fibres (Davydov \& Korneva, 2002). In the case of Shipleya (Gyroceliidae), in present study, the wall consists of an internal fibrillar matrix forming a thick layer with its own cell bodies, and an external coat of 20 layers of longitudinal muscle fibres. It is interesting to note that in 'higher' tapeworms there is a localization of muscle cells external to the cirrus sac wall along the peripheral layers of its muscle fibres. Another characteristic feature of the structure of this wall in 'higher' tapeworms is the presence within it of a fibrillar layer of variable thickness and location.

The prostatic glands associated with gonadoducts of the Eucestoda

Judging from available electron microscopical studies, the position of the accessory cells (prostatic glands) with male ducts of eucestodes varies between species. Specialized unicellular glands (prostatic glands) can occupy a position outside the cirrus sac, as in the cyclophyllidean Cylindrotaenia hickmani, and their ducts open into the vas deferens just prior to their entry into the cirrus sac (Jones, 1994). Such association between the prostatic glands and the vas deferens is rare in tapeworms. Such an association was indicated for the bothriocephallidean Eubothrium rugosum, a 'lower cestode' by Poddubnaya (2003 a). In the cases of the spathebothriidean cestodes Diplocotyle olrikii and Cyathocephalus truncatus and the bothriocephalideans Echinophallus wageneri and Paraechinophallus japonicus, well-developed prostatic glands occupy a position outside their cirrus sacs and open into the ejaculatory duct within the cirrus sac (Poddubnaya et al., 2005; Poddubnaya, 2007; Poddubnaya \& Mackiewicz, 2009). In the cases of other cestode species studied to date, such as diphyllobothriideans and proteocephalideans, the specialized prostatic glands occur within the cirrus sac and discharge their secretory products into the ejaculatory duct lumen (Korneva \& Davydov, 2001; Poddubnaya, 2002). In all of the abovementioned cestode species, the prostatic glands are specialized cells and their processes form ducts lined by peripheral microtubules. These ducts penetrate the epithelium and at their junction with the epithelial cytoplasm are found septate junctions and an eccrine mechanism for the discharge of their secretory granules. With respect to cyclophyllidean tapeworms, within the cirrus sac in Shipleya inermis (Gyroceliidae) and Sobolevicanthus gracilis (Hymenolepididae) sunken accessory cells producing electron-dense bodies connect with the epithelium of the ejaculatory duct via their cytoplasmic processes (Davydov \& Korneva, 2002, present study). According to Davydov and Korneva (2002), these epithelial cytons around ejaculatory duct are modified prostatic glands and such glands may represent a trait of 'higher' tapeworms. However, it should be noted that in another cyclophyllidean species of the family Nematotaeniidae, Cylindrotaenia hickmani, the presence of specialized unicellular prostatic glands external to the cirrus sac and opening into the vas deferens has been described (Jones, 1989, 1994).

\section{Cirrus armature in the Eucestoda}

Various types of cirrus microtriches have been described in ultrastructural studies of tapeworms. To our knowledge, in caryophyllidean cestodes uniform microtriches with knobshaped electron-dense apical cap have been described for Caryophyllaeus laticeps (see Davydov et al., 1994), and 
uniform filiform microtriches are present on the cirrus surface of Archigetes sieboldi (see Poddubnaya et al., 2003b). Uniform spiniform microtriches cover the cirrus of the spathebothriidean species Cyathocephalus truncatus and Diplocotyle olrikii (see Poddubnaya et al., 2005; Poddubnaya, 2007). In the case of bothriocephalideans, lamellar structures have been observed on the cirrus surface of Eubothrium rugosum (see Poddubnaya, 2003a), filiform microthriches with an long electron-lucent cap are reported for Triaenophorus nodulosus (see Korneva, 2002) and with a long electron-dense cap in Echinophallus wageneri (see Poddubnaya \& Mackiewicz, 2009). Mixed filiform and spiniform microtriches have been found in studied species of the Diphyllobothriidea, Proteocephalidea and Tetraphyllidea (Beveridge \& Smith, 1985; Korneva \& Davydov, 2001; Poddubnaya, 2002). Among the cyclophyllideans, different types of spiniform microtriches mixed with uniform filiform structures have been detected on the cirrus surface of Cylindrotaenia hickmani (see Jones, 1989) and spiniform microtriches in Sobolevicanthus gracilis and Parabisacanthes philactes (see Czapliński et al., 1984; Cielecka et al., 1994; Davydov \& Korneva, 2002). However, in Shipleya inermis, the luminal surface bears electron-dense extensions resembling spiniform microtriches, but unlike a 'true' microthrix forms they lack the basal plate between their basal region and cap; hence, we refer to them as 'microthrix-like structures'.

Another sclerotized feature of the cirrus, the so-called 'modified hooks' (see Poddubnaya \& Mackiewicz, 2009), has been referred to as 'spines' in almost all morphological and taxonomic studies (see Schmidt, 1986; Khalil et al., 1994). They are more typical of cyclophyllidean tapeworms and bothriocephalideans of the family Echinophallidae (Schmidt, 1986; Khalil et al., 1994). To date, there are only three TEM ultrastructural studies dealing with these sclerotized structures of the male terminal genitalia (Levron et al., 2008; Poddubnaya \& Mackiewicz, 2009; present study). In the case echinophallideans (Levron et al., 2008; Poddubnaya \& Mackiewicz, 2009) and cyclophyllidean Shipleya inermis (present study), the hooks of the cirrus have been identified as intracellular structures of the epithelial wall of the cirrus, which is consistent with the epithelial localization of the hooks. Based on these studies, it can be postulated that the numerous electron-dense bodies and vesicles, produced in the sunken cirrus cell bodies and filling the cirrus epithelial cytoplasm, participate in the hook formation and the hooks are derivatives of the cirrus epithelium. Within the Platyhelminthes, the neodermal hooks of the trematodes and cestodes have been postulated as being specialized intracellular structures within the syncytial epithelial wall by Lee (1972). The similar patterns in terms of the apparent epithelial formation of these hooks, suggests a common morphological origin of these neodermal hard structures in platyhelminths. Observed variations in the structure of different regions of these hooks in studied tapeworms are quantitative differences, which can be considered as species specific characters.
Another kind of hard structure is associated with the cirrus of the tapeworms of the order Cyclophyllidea, the copulatory stylet. SEM and TEM structural analyses of this stylet in the hymenolepidid Sobolevicanthus gracilis have shown that it has the form a hollow tube with an electron-dense wall (Cielecka et al., 1994; Davydov \& Korneva, 2002). Unfortunately, there is not any indication of the origin of this type of hard structure. It should, however, be noted that stylet-bearing copulatory organs with simple tubular cirrus stylets which represent intracellular specializations are a characteristic feature of many free-living Platyhelminthes (Martens \& Schockaert, 1981; Doe, 1982; Martens, 1984, 1986).

\section{Innervation of the cirrus sac}

The cirrus sac of Shipleya inermis (present study) is well supplied with nerve fibres containing large dense vesicles which run very closely to the muscle fibres and to fibrillar matrix of the sac wall and male reproductive ducts within the cirrus sac. The same observation has been made for Hymenolepis diminuta by Lumsden and Specian (1980). Halton and Gustafsson (1996) suggested that in the flatworms integration takes place through secretory neurons engaged in the synthesis and export of material by axonal transport in vesicles'. Innervation of the cirrus sac of $D i$ phyllobothrium dendriticum has been studied by Gustafsson (1985) who found that dense FMRF-IR nerve fibres extend through the longitudinal muscle layer of the sac wall and within the cirrus sac. Among the studied cestode species, it has demonstrated in Cylindrotaenia hickmani (see Jones, 1989) that the cirrus sac is a complex organ controlled by a complex nervous and muscle system. Furthermore, an accumulation of sensory endings around the genital atrium has been indicated for the diphyllobothriideans $D$. ditremum, D. dendtriticum (see Andersen, 1975) and D. latum (see Poddubnaya, 2002) and for the bothriocephallidean Spirometra erinacei (see Okino $\&$ Hatsushika, 1994), and Andersen (1975) has suggested that these receptors play a functional role as tangoreceptors in the processes of copulation.

\section{Conclusions}

Studies of the ultrastructure of the cestode cirrus sac support and add supplementary detail to previous light microscopical data and add new ultrastructural features as this structure exhibits considerable variability in different species, genera, families and orders of the Eucestoda. We are convinced that the ultrastructural characters of the cirrus sac will provide valuable clues for tracing phylogenetic relationships of tapeworm groups. With increasing knowledge of the ultrastructure of the copulatory apparatus of cestodes new traits will become available which can validly be utilized in phylogenetic systematics.

With respect to Shipleya inermis, data resulting from the present study of the cirrus sac supports the opinion on the existence strobilae containing the testes and the cirrus sac, previously referred to in the literature as 'male strobilae'. The well-developed cirrus sac of these strobilae includes 
internal seminal vesicles, the lumen of which is packed with spermatozoa, an ejaculatory duct with accessory sunken cells and an armed cirrus. In future ultrastructural investigations of other types of strobilae of $S$. intermis special attention will be given to comparative analyses of the morphology of the cirrus sac of the male, incompletely gonochoristic female and female stobilae, and the degree of development of the vitelline cells, testes, spermatozoa, oocytes and eggs in different types of the strobilae with the aim of understanding the 'Shiplea enigma'.

\section{Acknowledgements}

The present study was partly supported by the Russian Foundation for Fundamental Research project No. 09-0400342a to LP and by grants of RFBR - FEB RAS (no. 0904-98523) and FEB RAS (no. 09-III-A-06-218) to NP. The authors would like to thank the staff of the Centre of Electron Microscopy, Institute of Biology of Inland Waters, Borok, Russia for the technical assistance. Our thanks are due to Dr. D.I. Gibson for reading the manuscript and for valuable English corrections.

\section{References}

ANDERSEN, K. (1975): Ultrastructural studies on Diphyllobothrium ditremum and D. dendriticum (Cestoda, Pseudophyllidea), with emphasis on the scolex tegument and the tegument in the area around the genital atrium. Z. Parasitenkd, 46: 253 - 264. DOI: 10.1007/BF00418519.

BAER, J. G. (1940): Some avian tapeworms from Antigua. Parasitology, 32: $174-197$

BeVEridge, I., SMith, K. (1985): An ultrastructural study of the cirrus and vagina of Phyllobothrium vagans (Cestoda: Tetraphyllidea). Z. Parasitenkd, 71: $609-616$. DOI: $10.1007 / \mathrm{BF} 00925594$

BURT, D. D. R. (1939): On the cestode family Acoleidae, with a description of a new dioecious species Infula burhini gen. et sp. nov. Ceylon J. Sci, 21: 195-208

CieleckA, D., GrYTner-ZIECINA, B., Chromicz, L. (1994): Studies on the surface ultrastructure of Sobolevicanthus gracilis (Zeder, 1803) (Cestoda, Hymenolepididae). Acta Parasitologica, 39: 131 - 137

CoIL, W. H. (1970): Studies on the biology of the tapeworm Shipleya inermis Fuhrmann, 1908. Z. Parasitenkd, 35: 40-54. DOI: 10.1007/BF00259529

CZAPlińsKi, B., AESCHLIMANN, A., SzELENBAUMCiEleCKA, D. (1984): Scanning electron microscopy of the cirrus surface of some Hymenolepididae (Cestoda). Acta Parsitologica Polonica, 29: 59 - 62

Davydov, V. G ., Korneva, Z. V. (2002): Structure of the copulative apparatus of Sobolevicanthus gracilis (Cestoda: Cyclophyllidea). Parazitologiya, 36: 224 - 230 (In Russian)

Davydov, V. G., Poddubnaya, L. G., Kolesnikova, G. A. (1994): Ultrastructure of genital system ducts of Caryophyllaeus laticeps (Cestoda, Caryophyllidea). Parazitologiya, 28: 501 - 509
DiDYK, A. S., BuRT, M. D. B. (1998): Geographical, seasonal, and sex dynamics of Shipleya inermis (Cestoidea: Dioecocestidae) in Limnodromus griseus Gmelin (Aves: Charadriiformes). J. Parasitol, 84: 931 - 934

DoE, D. A. (1982): Ultrastructure of copulatory organs in Turbellaria. I. Macrostomum sp. and Microstomum sp. (Macrostomida). Zoomorphol., 101: 39 - 59. DOI: 10.100 7/BF00312029

DoE, D. A. (1986): Ultrastructure of the copulatory stylet and accessory spines in Haplopharynx quadristimulus (Turbellaria). Hydrobiologia, 132: 157 - 163. DOI: 10.100 7/BF00046243

Gustafsson, M. K. S. (1985): Cestode neurotransmitters. Parasitol. Today. 1: 72 - 75. DOI: 10.1016/0169-4758(85) 90046-8

Halton, D. W., Gustafsson, M. K. S. (1996): Functional morphology of the platyhelminth nervous system. Parasitology, 113: 47 - 72. DOI: 10.1017/S003118200006621X

JONES, M. K. (1989): Ultrastructure of the cirrus pouch of Cylindrotaenia hickmani (Cestoda, Nematotaeniidae). Int. J. Parasitol, 19: 919 - 930

JONES, M. K. (1994): Ultrastructure of the male accessory glands and sperm ducts of Cylindrotaenia hickmani (Cestoda, Cyclophyllidea). Acta Zoologica, 75: 269 - 275

Khalil, L. E. A., Jones A., Bray R. A. (1994): Keys to the cestode parasites of vertebrates. CAB International, Wallingford, U.K. 447 pp.

KoRnEVA, Z. V. (2002): Ultrastructural organization of reproductive system in Triaenophorus nodulosus (Cestoda, Pseudophyllidea). Zool. Zhurnal, 81: 1432 - 1438 (In Russian)

KorneVA, Z. V., DAVYdov, V. G. (2001): Ultrastructure of male reproductive system in three proteocephalidean cestodes. Zool. Zhurnal, 80: 921 - 928 (In Russian)

LEE, D. (1972): The structure of the helminth cuticle. $A d v$. Parasitol, 10: 347 - 377

LuMSDEN, R., SPECIAN, R. (1980): The morphology, histology and the fine structure of the adult stage. In: ARAI, H. P. (Ed) Biology of the Tapeworm, Hymenolepis diminuta. Academic Press, London, New York, pp. 157 - 280

Levron, C., Poddubnaya, L. G., Kuchta R., Freeman, M., WANG, Y.-H., SCHOLZ, T. (2008): SEM and TEM study of the armed male terminal genitalia of the tapeworm Paraechinophallus japonicus (Cestoda: Bothriocephalicdea). J. Parasitol, 94: 803 - 810. DOI: 10.1645/GE-1474.1 MARTENS, E. E. (1984): Ultrastructure of the spines in the copulatory organ of some Monocelididae (Turbellaria, Proseriata). Zoomorphol, 104: 261 - 265. DOI: 10.1007/BF00 312007

MARTENS, E. E. (1986): Comparative ultrastructure of copulatory organs having a stylet in the Proseriata (Turbellaria). Hydrobiologia, 132: 165 - 173. DOI: 10.1007/BF000 46244

MARTENS, E. E., SCHOCKAERT, E. R. (1981): Observations on the ultrastructure of the copulatory organ of Archilopsis unipunctata (Faricius, 1826) (Proseriata, Monocelididae). Hydrobiologia, 84: 277 - 285. DOI: 0018-8158/81/08430277/\$01.80 
OKINO T., HATSUSHIKA R. (1994): Ultrastructure studies on the papillae and the nonciliated sensory receptors of adult Spirometra erinacei (Cestoda, Pseudophyllidea). Parasitol. Res, 80: 454 - 458. DOI: 10.1007/BF00932690. PODDUBNAYA, L. G. (2002): Ultrastructure of reproductive ducts in Diphyllobothrium latum (Cestoda, Pseudophyllidea) males. Zool. Zhurnal, 81: 394 - 405 (In Russian)

PoDDUBnAYA, L. G. (2003a): Structure of reproductive system of the amphicotylide cestode Eubothrium rugosum (Cestoda, Pseudophyllidea). J. Evol. Biochem. Physiol, 39: 345 - 355. DOI: 10.1023/A:1026104110621

PoDDUBNAYA, L. G. (2003b): Ultrastructure of reproductive organs and ducts in the progenetic species Archigetes sieboldi (Cestoda, Caryophyllidea). Zool. Zhurnal, 82: 1038 - 1050 (In Russian)

PodDubnayA, L. G. (2007): Fine morphology of the cirrus sac and vagina of progenetic Diplocotyle olrikii (Cestoda: Spathebothriidea). Parazitologiya, 41: 299 - 308 (In Russian)

Poddubnaya, L., Mackiewicz, J. S. (2009): Ultrastructure of the cirrus sac of echinophallid tapeworms (Cestoda, Bothriocephalidea) and the terminology of cirrus hard structures. Int. J. Parasitol, 39: 381 - 390. DOI: 10.1016/ j.iipara.2008.07.008

Poddubnaya, L. G., Mackiewicz, J. S., BruŇAnskÁ, M., DEZFULI, B. S. (2005): Fine structure of the male repro- ductive ducts, vagina and seminal receptacle of Cyathocephalus truncatus (Cestoda: Spathebothriidea). Folia Parasitol, 52: 241 - 250

Poddubnaya, L. G., Mackiewicz, J. S., Kuperman, B. I. (2003): Ultrastructure of Archigetes sieboldi (Cestoda: Caryophyllidea): relationship between progenesis, development and evolution. Folia Parasitol, 50: 275 - 292

RAUSCH, R. L., RAUSCH, V. R. (1990): Reproductive anatomy and gametogenesis in Shipleya inermis (Cestoda: Dioecocestidae). Ann. Parasit. Hum.Comp, 65: 229 - 237.

RYZHIKOV, K. M., TOLKACHEVA L. M. (1981): Acoleidaetapeworms of the birds. Fundamentals of Cestodology, (Ed V. I. Freze), Moscow 'Nauka'. V. 10. 214 pp. (In Russian) SCHEll, S. C. (1959): The Shipleya enigma. Trans. Am. Microsc. Soc, 78: $352-354$

SCHMIDT, G. D. (1986): Handbook of tapeworm identification. CRC Press, Boca Raton. Florida, 675 pp.

Smith J. D., MCManus D. P. (1989): The physiology and biochemistry of cestodes. Cambridge University Press, Cambridge

SPASSKI, A. A., GubANOV N. M. (1959): An unusual form of dioecious cestodes. Trudy Instituta Morfologii Zhivotnykh im. A. N. Severtsova, Moscow, 27: 91 - 100 (In Russian)

Voge, M., Rausch R. (1956): Observations on Shipleya inermis Fuhrmann, 1908 (Cestoda: Acoleidae). J. Parasitol, $42: 547-551$

ACCEPTED MAY 31, 2011 